\title{
Numerical Simulation on Mechanical Characteristics of floor in Gob-side Entry Retaining of Deep Mine
}

\author{
Ming Yang 1, a, Xiang Liu ${ }^{2, b}$ and Yan Zhang ${ }^{3, c}$ \\ ${ }^{1}$ College of Energy and Safety, Anhui University of Seience and Technology, Huainan, Anhui, China \\ ${ }^{2}$ College of Energy and Safety, Anhui University of Seience and Technology, Huainan , Anhui, China \\ ${ }^{3}$ College of Energy and Safety, Anhui University of Seience and Technology, Huainan, Anhui, China \\ a 568165630@qq.com , b 851762260 @qq.com, c1457392152 @qq.com
}

Keywords: Gob-side Entry Retaining of Deep Mine; Mechanical Characteristics of floor; Numerical Simulation.

\begin{abstract}
This paper revealed the mechanical characteristics of floor in Gob-side Entry Retaining of Deep Mine according to the geological conditions and mining technical conditions of working face 1115(1) in Guqiao coal mine by using numerical simulation. The characteristics of the vertical stress distribution of strike and incline in the floor at different stages are obtained, which provides a theoretical basis for the prevention and control of floor heave.
\end{abstract}

\section{Introduction}

The problem of floor heave becomes more and more prominent with the increase of the depth of mining and the section of roadway. The bad floor heave not only adds a lot of maintenance work, but the safety and efficient production of coal mining face was also seriously affected. At present, the mechanism and deformation and damage characteristics of floor in Gob-side Entry Retaining have been studied. For example, the force and deformation characteristics of floor in Gob-side Entry Retaining have been studied by theoretical analysis in the literature 1 to 3, the deformation and failure characteristics of floor in the whole process of Gob-side Entry Retaining have been studied by similar simulation and numerical simulation in the literature 4 and 5. Obviously, the stress characteristics and evolution process of floor in the whole process of Gob-side Entry Retaining have not been studied before, and the stress is one of the main cause of the deformation and failure of the floor.

Based on this, taking the geological conditions of working face 1115(1) in Guqiao coal mine as the engineering background, the mechanical characteristics of floor in the whole process of Gob-side Entry Retaining have not been systematic studied in this paper, and the law of the stress evolution of its floor has been explorated.

\section{Engineering situation}

The working face $1115(1)$ in Guqiao coal mine is located at $-780 \mathrm{~m}$ levels, the maximum depth is $797 \mathrm{~m}$, the thickness of coal is $2.50 \sim 3.61 \mathrm{~m}$, the average thickness of it is $2.94 \mathrm{~m}$, and the incline of coal is $3 \sim 10$, with the average is $5^{\circ}$. The mining roadway is located in the $11-2$ coal seam,most of the direct top of it is composiitte roof, and the coal is directly covered by sandstone of the basic roof in some areas. The concrete paste material is used to fill during in Gob-side Entry Retaining,and the roadway was supported by anchor and net shotcreting,and the section of it is rectangle. The width and height of it are $5.0 \mathrm{~m}$ and $3.4 \mathrm{~m}$, and the section of it is $17.00 \mathrm{~m}^{2}$.

\section{Computational model and parameter}

Computational model. The computational model was established by FALC ${ }^{3 \mathrm{D}}$ based on working face $1115(1)$,and the length, width and height of it are $350 \mathrm{~m}, 265 \mathrm{~m}$ and $90 \mathrm{~m}$. The average incline angle is 
$0^{\circ}$,the thickness of coal is $3.5 \mathrm{~m}$, and the length of the working face in incline is $130 \mathrm{~m}$. The $3 \mathrm{~d}$ model was divided into 518580 units, with 540540 nodes. The horizontal displacement was fixed at left and right boundary of the model, and the vertical displacement was fixed at bottom boundary, the Vertical load on the top of model is the weight of the overlying strata. The three-dimensional model mesh is shown in Fig.1.

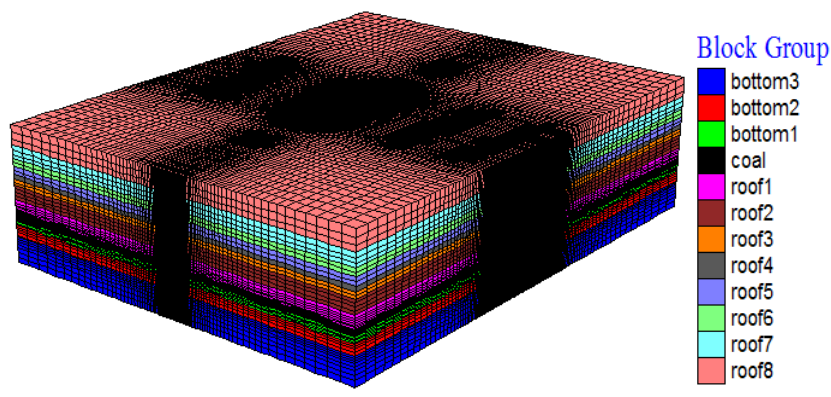

Fig. 1 The trellis of three-dimensional calculating model

Computational parameter. Combined with the analogy of the physical and mechanical parameters of rock strata near the working face and referring to other relevant documents, the effective rock mechanics parameters were finally determined as shown in Table 1.

Table 1 The mechanics parameters of rock mass

\begin{tabular}{cccccc}
\hline rock name & $\begin{array}{c}\text { density } \\
\left(\mathrm{kg} / \mathrm{m}^{-3}\right)\end{array}$ & $\begin{array}{c}\text { bulk modulus } \\
(\mathrm{GPa})\end{array}$ & $\begin{array}{c}\text { shear modulus } \\
(\mathrm{GPa})\end{array}$ & $\begin{array}{c}\text { cohesion } \\
(\mathrm{MPa})\end{array}$ & $\begin{array}{c}\text { internal friction angle } \\
\left({ }^{\circ}\right)\end{array}$ \\
\hline fine sandstone & 2600 & 6.5 & 6.0 & 3.0 & 40 \\
mudstone & 2400 & 2.1 & 1.2 & 1.2 & 25 \\
siltstone & 2600 & 5.2 & 3.7 & 3.9 & 45 \\
sandy mudstone & 2500 & 5.2 & 3.4 & 2.2 & 35 \\
medium-sandstone & 2700 & 4.8 & 3.6 & 1.6 & 35 \\
11-2 coal & 1400 & 1.5 & 0.8 & 1.1 & 28 \\
filling body & 1873 & 6.1 & 4.4 & 2.1 & 37 \\
\hline
\end{tabular}

\section{Simulation results and analysis}

\subsection{The characteristics of vertical stress distribution of roadway floor during primary mining.}

Distribution characteristics of inclined vertical stress. The incline vertical stress distribution of roadway floor which $0.5 \mathrm{~m}$ below its surface in front of working face of is shown in Fig.2.

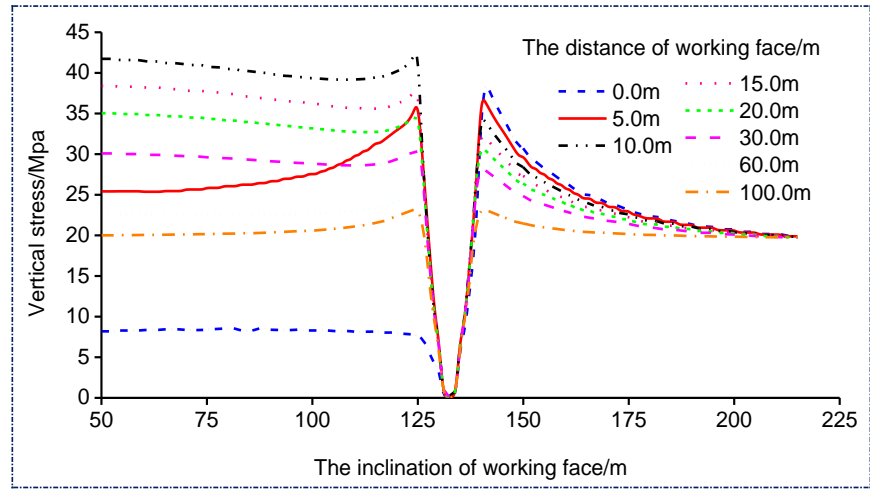

Fig.2 The incline vertical stress distribution of roadway floor in front of working face during primary mining

Figure 2 shows: There was a supporting stress increase area on both sides of roadway floor in front of working face. The supporting pressure on both sides of the floor was symmetrical distribution which over than $60 \mathrm{~m}$ ahead of working face, and the peak value tends to be the same basically, which 
indicates that the rock layer of roadway floor is less affected by the mining movement of working face. The supporting pressure on both sides of the floor is no longer symmetrical distribution with in $60 \mathrm{~m}$ in front of working face for the influence of strong mining. The supporting pressure of mining coal side was bigger than no mining coal side among the range of $10 \sim 30 \mathrm{~m}$ ahead of working face, and the supporting pressure of no mining coal side was bigger than mining coal side.

The incline vertical stress distribution of roadway floor which $0.5 \mathrm{~m}$ below its surface behind of working face of is shown in Fig.3.

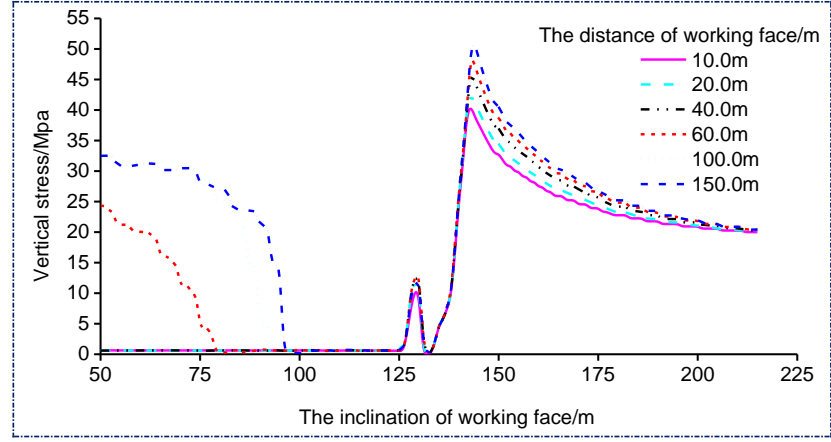

Fig.3 The incline vertical stress distribution of roadway floor behind of working face during primary mining

Figure 3 shows: The supporting pressure of floor under side solid coal continuously increased with the increase of distance from the working face, which the position of peak value of it gradually transferred to deep coal. The supporting pressure of it had little change with in $20 \mathrm{~m}$ behind of working face, and increase rapidly among the range of $20 \sim 60 \mathrm{~m}$, slow growth among the range of $60 \sim 100 \mathrm{~m}$, and it tended to be stable beyond $100 \mathrm{~m}$.

Distribution characteristics of strike vertical stress. The strike vertical stress distribution of different layers in the middle of roadway floor is shown in Fig.4.

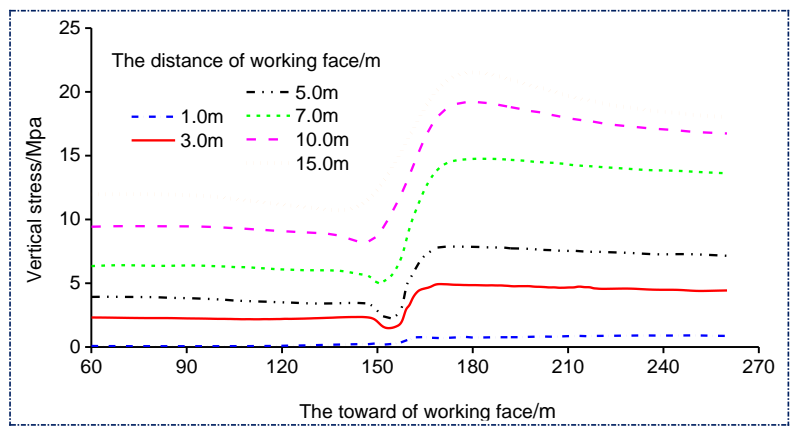

Fig.4 The strike vertical stress distribution of roadway floor during primary mining

Figure 4 shows: The increase of vertical stress of roadway floor not the same with the different depth of the floor surface of the roadway. The vertical stress of roadway floor is increased with depth increases no matter in front or back of working face. The vertical stress in front of the working face is bigger than that back of it for the effect of supporting pressure in the working face.

\subsection{The characteristics of vertical stress distribution of roadway floor during secondary mining.}

Distribution characteristics of incline vertical stress. The incline vertical stress distribution of roadway floor which $0.5 \mathrm{~m}$ below its surface in front of working face of is shown in Fig.5. 


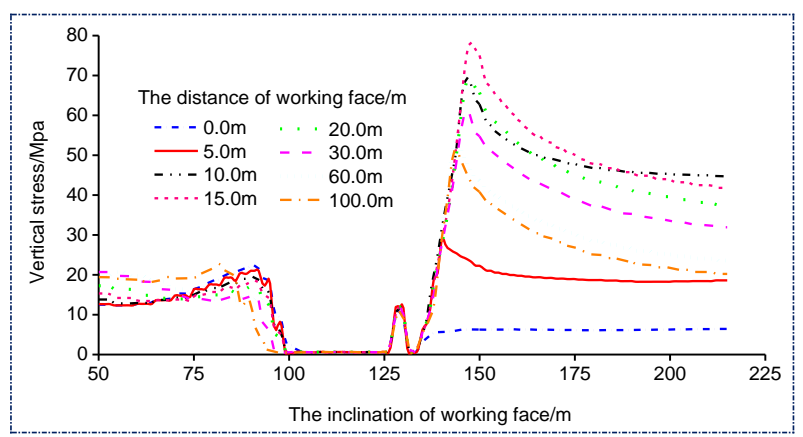

Fig.5 The incline vertical stress distribution of roadway floor in front of working face during secondary mining

Figure 5 shows: The supporting pressure of floor under side solid coal continuously increased with the increase of distance from the working face with in $15 \mathrm{~m}$ in front of working face. The supporting pressure of it began to remit drop off, and it tend to be stable among the range of $60 \sim 100 \mathrm{~m}$.

Distribution characteristics of toward vertical stress. The strike vertical stress distribution of different layers in the middle of roadway floor is shown in Fig.6.

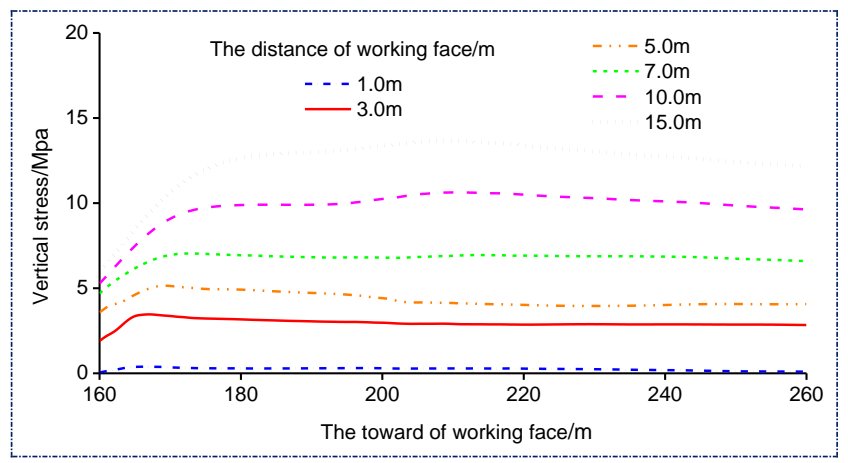

Fig.6 The strike vertical stress distribution of roadway floor during secondary mining

Figure 6 shows: The vertical stress of roadway floor in front of the working face increased as the depth increase. The vertical stress of roadway floor increased and then stabilized with the increase of distance from the working face.

\section{Summary}

The incline supporting pressure was a symmetrical distribution beyond $60 \mathrm{~m}$ in front of the working face, and no longer symmetrical distribution for mining, and back of the working face increased and then stabilized with the increase of distance from the working face. The strike vertical stress of roadway floor is increased with depth increases, and the front is bigger than the back. The strike supporting pressure increased and then stabilized with the increase of distance from the working face, and the vertical stress of roadway floor in front of the working face increased as the depth increases during secondary mining.

\section{References}

[1] HUA Xinzhu, LI Yingfu. Mechanics analysis on floor deformation of gob-side entry retaining and prevention and control of floor heave[J]. Journal of China Coal Society, 2016, 41(7): 1624-1631.

[2] HUA Xinzhu, LU Xiaoyu, LI Yingfu. Prevention and control technology of floor heave in gob-side entry re-taining with large section of deep mine[J]. Coal Science and Technology, 2013, 41(9): 100-104. (in Chinese ) 
[3] WEI Xihe, LIN Dongcai, XU Chunzhao. The floor stress and deformation characteristics of deep roadway along goaf $[\mathrm{J}]$. Industrial Safety and Environmental Protection, 2013, 39(1): 4-9. (in Chinese )

[4] HUA Xinzhu, YANG Ming, LIU Qingjie, et al. Model test on evolution mechanism of floor heave in gob-side retaining entry of deep mine[J]. Journal of Mining \& Safety Engineering, 2018, 35(1): 1-9. (in Chinese )

[5] HUA Xinzhu, LI Zhihua, LI Yingfu, et al. Analysis on floor heave features of large cross section gob-side entry retaining in deep mine[J]. Coal Science and Technology, 2016, 44(9): 26-30. (in Chinese ) 